\title{
Quadricuspid aortic valve: case report and literature review
}

\author{
Guilherme de Menezes SUCCI ${ }^{1}$ \\ José Ernesto SUCCI ${ }^{1}$ \\ Fabiana Moreira Passos SUCCI ${ }^{1}$ \\ Camila de Menezes SUCCI ${ }^{2}$ \\ Alexandre CZEZACKI ${ }^{1}$
}

\begin{abstract}
Introduction: Quadricuspid aortic valve is a rare anatomical abnormality, its incidence ranging from $0.008 \%$ to $0.033 \%$. Case Report: We describe the case of a female patient with a quadricuspid aortic valve. The direct visualization showed a type E quadricuspid aortic valve. After complete excision of the valve, it was replaced by a $23 \mathrm{~mm}$ biological prosthesis. Postoperative recovery was uneventful. Discussion: Since the first case, described in 1862, fewer than 200 cases have been diagnosed so far in world literature. Given its frequent association with other cardiac malformations, it is important that physicians seek their preoperative diagnosis.
\end{abstract}

Keywords: Aortic valve. Congenital abnormalities. Diagnostic Techniques, Surgical.

\section{INTRODUCTION}

Quadricuspid aortic valve is a rare anatomical malformation, with few cases described in the literature. Its incidence ranges from $0.008 \%$ to $0.033 \%$ [1]. It may be presented as an isolated cardiac malformation, but in some cases there are other heart defects, such as coronary abnormalities (mainly ostial anomalies), atrial septal defect, or ventricular septal defect [2]. Diagnosis by transthoracic echocardiography is difficult, with reports of diagnosis only with intraoperative direct observation or by transesophageal echocardiography (either pre-op or intraop) [3].

We describe the case of a 49-year-old patient diagnosed with aortic regurgitation, whose diagnosis was made only intraoperatively.

\section{CASE REPORT}

We present a case of a 49-year-old Caucasian female, who had been complaining of fatigue due to moderate exertion for 8 months, which had worsened to minor exertion for the last 2 months.
The patient had a previous diagnosis of aortic valve dysfunction (aortic insufficiency) with regular visits to her personal cardiologist for the last twelve years. During the follow-up period, the patient had remained asymptomatic until 8 months ago, when she started to complain of fatigue and dyspnea during moderate exertion. Two months before admission, dyspnea had begun to present on light exertion, associated with vertigo and sporadic tachycardia. There were no reports of chest pain, syncope, cough, expectoration, fever, or weight loss in the related period.

A transthoracic echocardiogram was performed, showing a tricuspid aortic valve with significant aortic regurgitation and with mild left ventricular dysfunction. A coronary angiography revealed normal coronary arteries without obstruction.

The patient underwent surgical treatment for aortic valve replacement under general anesthesia and access through median sternotomy. Cardiopulmonary bypass was initiated with cannulation of the aorta and inferior and superior vena cava. When moderate hypothermia at $28^{\circ} \mathrm{C}$ was achieved, aortic cross clamping was performed. After oblique aortotomy, a quadricuspid

\footnotetext{
${ }^{1}$ Faculdade São Leopoldo Mandic, Curso de Medicina. Rua José Rocha Junqueira, 13, Swift, 13045-755, Campinas, SP, Brasil. Correspondência para / Correspondence to: GM SUCCI. E-mail: <guilherme.succi@slmandic.edu.br>.

${ }^{2}$ Hospital Bandeirantes. São Paulo, SP, Brasil.

$\boldsymbol{\nabla v} \boldsymbol{\nabla}$

Como citar este artigo / How to cite this article

Succi GM, Succi JE, Succi FMP, Succi CM, Czezacki A. Quadricuspid aortic valve: case report and literature review. InterAm J Med Health. 2018;1(1):e201801002.
} 
aortic valve was visualized, without prior diagnosis by transthoracic echocardiography (figure 1). Cardioplegia was administered through the coronary ostia, followed by retrograde cardioplegia delivered through a cannula placed in the coronary sinus.

Direct visualization of the aortic valve showed a quadricuspid valve, with three cusps of equivalent size, and a fourth and larger cusp. After complete excision of the valve, replacement was performed with a $23 \mathrm{~mm}$ biological bovine pericardium prosthesis (Labcor Inc). The CPB and aortic cross clamping time were 65 min and 54 min, respectively.

The postoperative course was uneventful, and the patient was discharged on the fifth postoperative day.

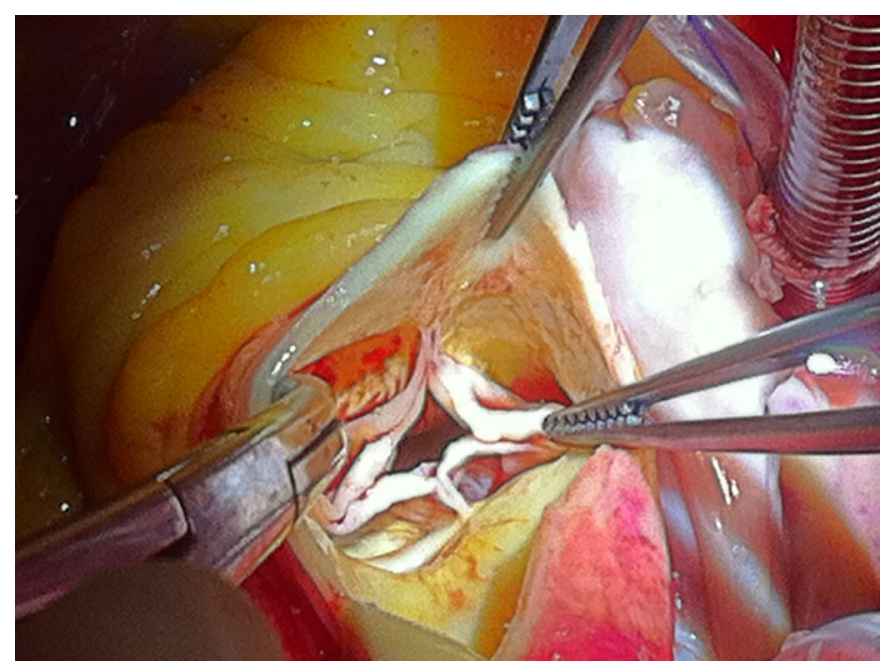

Figure 1. Intraoperative view of the aortic valve. Four cusps can be clearly identified.

\section{DISCUSSION}

The presentation of four cusps in the aortic valve is a rare, probably underdiagnosed condition. From the various congenital abnormalities affecting this valve, the most frequent is the bicuspid aortic valve, occurring in approximately 2 percent of the general population [4]. Although very infrequent, an interesting piece by Leonardo da Vinci from between 1512 and 1513 was found, depicting a quadricuspid aortic valve [5]. The first case described in medical literature was presented in $1862[5,6]$, and since then, fewer than 200 cases have been described so far $[7,8]$.

In 1973, Hurwitz and Roberts [9] proposed an anatomical classification of quadricuspid semilunar valves, based on anatomic studies of 8 quadricuspid pulmonic valves and 2 quadricuspid aortic valves, after examination of 6,000 necropsies. The authors encountered seven different anatomic types, which were classified from $A$ to $G$, in terms of the size of each cusp. The case described in our report could be classified into type $E$, with one bigger cusp and three smaller cusps. Feldman et al., in 1990 [1] reported an incidence of only 8 cases of quadricuspid aortic valve in more than 60,000 echocardiographic examinations analyzed, with an incidence rate of $0.013 \%$. Often, due to the low incidence of this valvar anomaly, echocardiogram is unsuitable for definitive diagnosis.

Much like in the case described by Denker and Stagmo [10], our patient did not obtain a preoperative diagnosis via transthoracic echocardiography. It is probable that the unusual character of this anatomical variation leads to its low diagnosis through imaging methods, and even in some less careful necropsy analysis.

The presence of a quadricuspid aortic valve, although rare, may be associated with other cardiac malformations, which may require proper surgical correction. Therefore, it is important that physicians consider the possibility of such diagnosis prior to surgical intervention.

\section{REFERENCES}

1. Gouveia S, Martins JDF, Costa G, Paramés F, Freitas I, Rebelo $\mathrm{M}$, et al. Válvula aórtica quadricúspide: casuística de 10 anos e revisão da literatura. Rev Port Cardiol. 2011;30(11):849-854.

2. Tsukioka K, Nobara H, Takano T, Wada Y, Amano J. Quadricuspid aortic valve with ascending aortic aneurysm: a case report and histopathological investigation. Ann Thorac Cardiovasc Surg. 2011;17(4):418-21. doi: 10.5761/atcs.cr.10.01567

3. Das A, Singh U, Rajashekar P. Quadricuspid aortic valve: A rare intraoperative diagnosis by transesophageal echocardiography. Ann Card Anaesth. 2018;21(1):95-6. doi: 10.4103/aca. ACA_114_17

4. Roberts WC. The congenitally bicuspid aortic valve. A study of 85 autopsy cases. Amer J Cardiol. 26:72-83,1970.

5. Ashrafian H, Harling L, Athanasiou T. Leonardo da Vinci and the first portrayal of quadricuspid semilunar valves and the nodules of Arantius. Int J Cardiol. 2013;165(3):560-1. doi: 10.1016/j.ijcard.2012.09.010

6. Tutarel O. The quadricuspid aortic valve: a comprehensive review. J Heart Valve Dis. 2004;13(4):534-7.

7. Feldman BJ, Khandheria BK, Warnes CA, Seward JB, Taylor $\mathrm{CL}$, Tajik AJ. Incidence, description and functional assessment of isolated quadricuspid aortic valves. Am J Cardiol. 
1990;65(13):937-8. doi: 10.1016/0002-9149(90)91446-D

8. Timperley J, Milner R, Marshall AJ, Gilbert TJ. Quadricuspid aortic valves. Clin Cardiol. 2002;25(12):548-52. doi: 10.1002/ clc.4950251203

9. Hurwitz LE, Roberts WC. Quadricuspid semilunar valve. Am J Cardiol. 1973;31(5):623-6. doi: 10.1016/00029149(73)90332-9.
10. Dencker M, Stagmo M. Quadricuspid aortic valve not discovered by transthoracic echocardiography. Cardiovasc Ultrasound. 2006;4:41. doi: 10.1186/1476-7120-4-41 